\title{
Effectively Addressing Human Immunodeficiency Virus Disparities Affecting US Black Women
}

\author{
Erin L.P. Bradley, Angelica Geter, Ashley C. Lima, Madeline Y. Sutton, and Donna Hubbard McCree
}

\begin{abstract}
Black women have disproportionately higher rates of human immunodeficiency virus (HIV) infection, and low percentages being linked to care and becoming virally suppressed, compared with women of other races/ethnicities. To date, few evidence-based HIV prevention and care interventions tailored for black women exist. We highlight three essential factors to consider in designing culturally and gender-appropriate studies to address HIV-related disparities affecting black women: (1) social determinants of HIV risk, (2) determinants of equity, and (3) perceptions of black women's sexuality. Synergy between a strong evidence base and developing strong partnerships could accelerate progress toward HIV-related health equity for black women.
\end{abstract}

Keywords: black/African American women; health disparity; health equity; HIV/AIDS; social determinants; United States

\section{Introduction}

Disparity, which can be defined as a lack of similarity or equality; inequality; difference, ${ }^{1}$ is a word that has characterized human immunodeficiency virus (HIV) diagnoses and outcomes for black/African American women (referred to as black women) since the 1980s, when acquired immunodeficiency syndrome (AIDS) was first recognized in the United States. ${ }^{2}$ Although black women experienced the largest decline in HIV diagnoses rates among women from 2010 to 2014, annual disparities between black women and their white counterparts persist. ${ }^{3}$ In $2016,61 \%$ of HIV diagnoses in women occurred among black women, although they comprised $13 \%$ of the US female population. ${ }^{4}$ The diagnosis rate among black women in 2016 was 15 times that seen in white women. ${ }^{4}$ Recent estimates show 1 in 54 black women compared with 1 in 941 white women may be diagnosed with HIV in their lifetime, if rates remain the same. ${ }^{5}$

The causes of these disparities are complex, extend beyond individual risk behaviors (e.g., condom use), and include social and structural factors, such as inequitable access to health care, stigma, and higher community levels of some sexually transmitted infections (STIs) that increase HIV risk. ${ }^{6,7}$ Compared with women in other racial/ethnic groups, black women report higher levels of condom use during heterosexual intercourse, ${ }^{6,8,9}$ the primary mode of HIV transmission among women. ${ }^{4}$ This underscores that the socioecological environments in which risk behaviors occur may increase black women's risk for HIV infection. ${ }^{6}$

Benefits of early diagnosis, linkage to care, viral suppression, and pre-exposure prophylaxis (PrEP, a medication to prevent HIV infection) in reducing HIV transmission are well known. ${ }^{10}$ However, PrEP use among black women is virtually nonexistent, ${ }^{11}$ possibly due to a lack of targeted efforts for this group. Moreover, results from research studies and national surveillance data highlight key social and structural challenges hindering care seeking among black women living with HIV. ${ }^{12}$ Compared with their white and Hispanic/ Latina counterparts, a lower percentage of black women

Division of HIV/AIDS Prevention, National Centers for HIV, Viral Hepatitis, STD, and TB Prevention, Centers for Disease Control and Prevention, Atlanta, Georgia.

*Address correspondence to: Erin Bradley, PhD, MPH, Division of HIV/AIDS Prevention, National Centers for HIV, Viral Hepatitis, STD, and TB Prevention, Centers for Disease Control and Prevention, 1600 Clifton Road NE, MS E-45, Atlanta, GA 30329, E-mail: ebradley3@cdc.gov

(c) Erin L.P. Bradley et al. 2018; Published by Mary Ann Liebert, Inc. This Open Access article is distributed under the terms of the Creative Commons License (http://creativecommons.org/licenses/by/4.0), which permits unrestricted use, distribution, and reproduction in any medium, provided the original work is properly cited. 
are linked to HIV care ${ }^{13,14}$ and virally suppressed. ${ }^{13,15}$ These disparities warrant concerted efforts, including prioritizing HIV prevention, treatment, and care, to reduce the disproportionate HIV burden for black women.

Effectively addressing HIV-related disparities will depend, in part, on developing and implementing tailored approaches for black women that are informed by a strong evidence base. To date, there are few culturally tailored, evidence-based HIV interventions for black women. In this perspectives article, we highlight three essential factors for researchers to consider in designing culturally and gender-appropriate studies to address HIV-related disparities affecting black women: (1) social determinants of HIV risk, (2) determinants of equity for black women, and (3) perceptions of black women's sexuality.

\section{Social Determinants of HIV}

The existing body of research suggests social determinants of HIV (SDH) for black women include proximate and distal factors that contribute to disparities between black and white women. For example, higher incarceration and mortality rates among black men contribute to a sex ratio imbalance that may inadvertently promote concurrent partnerships. ${ }^{6,16}$ Assortative mixing patterns (having partners of the same race) in networks with a higher prevalence of undiagnosed and untreated HIV/STIs, especially in the southern United States, increase transmission risk, even with less risky sexual behavior. ${ }^{17,18}$ The effects of these partnership and network-related factors are exacerbated by poverty. ${ }^{6,19}$ Other factors such as HIV stigma, ${ }^{20}$ difficulty accessing quality health care, or navigating health care systems ${ }^{12}$ can worsen HIV prevention and care engagement outcomes for black women.

It is imperative that knowledge from SDH research be reflected in all aspects of research studies with black women, including developing research questions, designing and implementing studies, and interpreting findings. Just as researchers and practitioners have aligned HIV prevention and care efforts with current scientific knowledge (e.g., prioritizing sustained viral suppression, PrEP use, and integrated behavioral and biomedical approaches), disparities-focused research and programmatic efforts must also align with the current state of the science regarding social and structural factors that best explain disparate rates of HIV diagnoses and poor outcomes for black women (Table 1).

\section{Determinants of Equity}

Devoting research attention to determinants of equity that are linked to SDH is also fundamental. While $\mathrm{SDH}$ are contextual factors that explain why black women are more likely than white women to acquire HIV even with less risky behavior, social determinants of equity explain why contexts differ for many black women compared with their white counterparts. ${ }^{21}$ For example, access to high-quality HIV prevention and care services (structural factor) can differ for some black women compared with white women because of racism (determinant of equity). Racism, defined by Jones as a system that "structures opportunity and assigns value based on the social interpretation of how one looks," ${ }^{21}$ is a determinant of equity with historical foundations for black women that date back to slavery and continue to impact modern-day health care and sexual health. ${ }^{21,22}$ Gynecologic surgeries performed on enslaved black women without consent or anesthesia, and forced permanent sterilizations mostly on black and Hispanic women/Latinas to decrease "undesirable" minority children from "promiscuous" women, ${ }^{22}$ provide some historical context for understanding medical distrust reported by some black women. $^{23}$

Additionally, racism in health care settings (explicit or implicit) can discourage black women from initiating or continuing care, and can negatively affect the quality of their care. ${ }^{23}$ Socioecological models can provide frameworks for understanding and intervening on racism and key SDH at individual, interpersonal, community, and societal levels. ${ }^{24}$ Collaborative, multidisciplinary, and systems-level research that ethically engages black women and their health care providers to further explore racism and distrust, and remove them as health care barriers, is vitally needed to bolster health care engagement (Table 1).

\section{Perceptions of Black Women's Sexuality}

Many researchers, practitioners, and policy makers may be unaware of ways that historical representations of black women's sexuality can shape perceptions of HIV risk. Historically, black women's sexuality has not been their own to define. Stripped of their sexual agency during slavery, some of black women's earliest experiences in the United States included public exhibition as sexual curiosities, ${ }^{25}$ sexual abuse and reproductive exploitation, ${ }^{26}$ and involuntary scientific experimentation. ${ }^{22}$ The residual effects of black women's sexual exploitation range from advances in modern-day reproductive medicine ${ }^{22}$ 
Table 1. Examples of Culturally and Gender-Appropriate Research to Advance HIV-Related Health Equity for Black Women

\begin{tabular}{lcc}
\hline Disparities-focused study aim & $\begin{array}{c}\text { Study that addresses key social and } \\
\text { structural factors }\end{array}$ & Collaborative and multidisciplinary approach
\end{tabular}

\begin{tabular}{l}
\hline HIV care engagement \\
\hline Improve black women's health \\
care engagement by equipping \\
providers and frontline staff \\
with knowledge, attitudes, and \\
practices to provide culturally \\
and gender-appropriate ${ }^{\mathrm{a}}$ care \\
Key factors: \\
- Determinants of equity \\
- Perceptions of black women's \\
sexuality
\end{tabular}

Improve black women's health care engagement by reducing barriers to accessing highquality HIV-related prevention and care services

Key factors:

- Social determinants of health

- Determinants of equity
1. Develop and test the efficacy of culturally and gender-appropriate patient care education/training for providers and frontline staff

Note: Formative research with HIV-positive and HIV-negative black women (engaged in care and not engaged) that identifies barriers, facilitators (including resilience), and appropriate solutions is likely needed to inform the development of training materials 2. Implement and evaluate the effect of requirements to complete CME credits in areas related to racial or cultural bias on black women's care engagement and perceptions of the quality of care received

3. Assess attitudes and beliefs of providers and frontline staff regarding black women's sexuality, and ways they might affect interactions with and recommendations or treatment plans for black women Note: Study design could be informed by experimental social psychology literature on prejudice or implicit bias

1. Conduct an organization-level evaluation of health care facility policies and practices to identify aspects that might impede care access for some black women (e.g., hours of operation, efficiency of operations [affordable service, but lengthy wait times], costs and/or difficulty navigating payment assistance processes, negative patient-staff interactions)
Key partners for PIs to involve might include:

- Black women (HIV-positive and/or HIV-negative) and advocates-inform appropriateness of research questions, methods, interpretation of findings, implications, solutions

- Trusted community partners such as womenserving, faith-based, or other organizations actively engaged with black women-engaging black women in the research process

- Behavioral scientist, health education specialist, health communications specialistdevelopment and testing of training - Health care provider-clinical practice perspective

- Medical sociologist or other social scientist (e.g., social psychologist, anthropologist, historian)knowledge of historical context affecting black women's engagement with health care providers and systems

Key partners for Pls to involve might include:

- Black women (HIV-positive and/or HIV-negative) and advocates-insight regarding barriers and facilitators

- Trusted community partners-engaging black women in the research process

- Medical sociologist or other social scientistknowledge of historical context affecting black women's engagement with health care providers and systems

- Health care provider-clinical practice perspective

- Health policy analyst-expertise in evaluating organizational policies

\begin{tabular}{|c|c|c|}
\hline \multicolumn{3}{|c|}{ HIV testing and linkage to care or prevention services } \\
\hline $\begin{array}{l}\text { Reduce HIV/STIs in black sexual } \\
\text { networks in geographic areas } \\
\text { with high HIV prevalence or } \\
\text { incidence } \\
\text { Key factor: } \\
\text { - Social determinants of health }\end{array}$ & $\begin{array}{l}\text { 1. Evaluate community-based (including } \\
\text { grassroots) "test and treat" strategies that } \\
\text { identify undiagnosed persons, link HIV- } \\
\text { positive persons to HIV care and high-risk } \\
\text { negative persons to prevention services } \\
\text { (e.g., PrEP). }\end{array}$ & $\begin{array}{l}\text { Key partners for Pls to involve might include: } \\
\text { - Black women (HIV positive and/or HIV negative) } \\
\text { and advocates-insight regarding strategies } \\
\text { - Health departments, other providers, CBOs- } \\
\text { testing and care } \\
\text { - Trusted community partners-engaging } \\
\text { community members }\end{array}$ \\
\hline $\begin{array}{l}\text { Improve access to PrEP for black } \\
\text { women } \\
\text { Key factor: } \\
\text { - Social determinants of HIV }\end{array}$ & $\begin{array}{l}\text { 1. Assess the economic cost and benefit/public } \\
\text { health impact of scaling up PrEP for women } \\
\text { in high-prevalence areas } \\
\text { 2. Model the effects of scaling up PrEP for black } \\
\text { women on HIV incidence and on disparities } \\
\text { 3. Evaluate preparedness of women's health } \\
\text { care providers regarding PrEP readiness } \\
\text { screening and how to prescribe/help women } \\
\text { navigate PrEP access }\end{array}$ & $\begin{array}{l}\text { Key partners for Pls to involve might include: } \\
\text { - Health economist-expertise in cost analysis } \\
\text { - Clinical care providers, including physicians, } \\
\text { nurse practitioners and physician assistants- } \\
\text { operationalizing increased PrEP access } \\
\text { opportunities for black women }\end{array}$ \\
\hline
\end{tabular}

Funding for culturally and gender-appropriate research with black women will require grassroots efforts by black women in local communities and in gatekeeper positions to raise awareness and engage policy makers to request funding.

${ }^{a}$ Culturally and gender-appropriate care considers intersectionality (combined effects of race and gender) that can create experiences for black women that differ from those of men or other women. For example, conscious or unconscious bias informed by hypersexualized images or other negative perceptions of black persons might influence provider engagement and treatment plans for black persons. For black women, in addition to race, gender-specific attitudes or beliefs might influence provider engagement and treatment plans.

CBO, community based organization; CME, continuing medical education; HIV, human immunodeficiency virus; PI, principal investigator; PrEP, preexposure prophylaxis; STI, sexually transmitted infection. 
to ubiquitous misperceptions and stereotypes that overemphasize black women's sexuality. ${ }^{25}$

Dismantling faulty perceptions about black women's sexuality is key because it perpetuates a view of black women as more "promiscuous," "irresponsible," or "reckless" than women of other races/ethnicities, despite research findings that demonstrate otherwise. ${ }^{6,8,9}$ These stereotypes have the potential to bias the research agenda away from addressing SDH to a disproportionate focus on individual behavior. Similarly, these stereotypes create the potential for misperceptions to influence practitioners' assumptions about, interactions with, and recommendations or treatment plans for black women, even outside of the practitioners' awareness or intent. ${ }^{23}$ Consequently, engaging sociologists, anthropologists, and historians in multidisciplinary research can yield valuable insight for practitioners and policy makers who are informed by research findings (Table 1).

\section{Conclusion}

Reducing or eliminating the disproportionate adverse effects of HIV-related disparities on black women is achievable, and could be considered a public health imperative and an ethical responsibility. Achieving equity will require an intentional paradigm shift in the current approach to HIV prevention and care research with black women at risk of or living with HIV. This means designing studies that demonstrate careful consideration of gender and cultural factors, and prioritize addressing social and structural factors that increase black women's vulnerability to HIV infection or poor outcomes (Table 1). Attention to key SDH, racism as a determinant of equity, and perceptions of black women's sexuality is important. Using social ecological frameworks provides a comprehensive lens for developing research questions, designing and implementing studies, and interpreting findings. ${ }^{24}$ Furthermore, conducting research to identify where disparities are most pronounced (e.g., specific subpopulations or geographic locations) and monitoring progress in closing gaps over time are paramount. ${ }^{3}$

Research highlighting the critical role of sexual network characteristics, ${ }^{6,16-19}$ social and economic factors that affect sexual partnerships, ${ }^{6,19}$ and challenges accessing or utilizing quality health care ${ }^{12}$ has laid the foundation for disparities-focused epidemiologic and intervention research with black women. However, additional studies that evaluate strategies to address $\mathrm{SDH}$ are needed. For example, microenterprise approaches (e.g., business education and support, financial counsel- ing, loans) to address poverty as a key SDH have shown promise in studies internationally and warrant additional research attention domestically. ${ }^{27}$ Health services research to increase PrEP uptake among HIV-negative black women and improve care linkage and retention for black women living with HIV also provides important opportunities to address disparities. Valuable insight may also be gained from identifying factors that promote resilience among black women (e.g., spirituality, social support). Therefore, opportunities to build upon promising findings and strengthen the evidence base to decrease HIV gaps for black women remain.

Benefits of advances in HIV prevention and care are not being experienced equally across populations. ${ }^{4}$ Adjustments are needed to ensure that black women are not left behind in global efforts to eliminate new HIV infections, AIDS-related deaths, and HIV/AIDS-related discrimination. Promoting an evidence-informed narrative about black women's HIV-related risk and aligning research priorities with current scientific evidence are essential, and will provide a strong foundation for creating culturally tailored interventions to eliminate disparities. Additionally, a collective investment in developing and implementing a suite of culturally and gender-appropriate public health interventions is needed. Synergy between a strong evidence base and strong partnerships between researchers, clinicians, public health agencies, professional societies, community members and advocates, and entities from public and private sectors could accelerate progress toward effectively addressing social and structural factors that create or sustain HIV-related disparities that negatively affect black women.

\section{Author Disclosure Statement}

No competing financial interests exist. The findings and conclusions in this report are those of the authors and do not necessarily represent the official view of the Centers for Disease Control and Prevention.

\section{References}

1. Disparity. (n.d.). Available at www.dictionary.com/browse/disparity. Accessed August 14, 2018.

2. Centers for Disease Control and Prevention. Current trends update: acquired immunodeficiency syndrome-United States, 1981-1988. MMWR. 1989;38:229-232, 234-236.

3. McCree DH, Sutton M, Bradley E, et al. Changes in the disparity of HIV diagnosis rates among black women-United States, 2010-2014. MMWR. 2017:66:104-106.

4. Centers for Disease Control and Prevention. HIV surveillance report: diagnoses of HIV infection in the United States and dependent areas. 2016 Vol. 28. Available at https://www.cdc.gov/hiv/library/reports/hivsurveillance.html. Accessed May 22, 2018.

5. Hess KL, Xiaohong H, Lansky A, et al. Lifetime risk of a diagnosis of HIV infection in the United States. Ann Epidemiol. 2017;27:238-243. 
6. Aral SO, Adimora AA, Fenton KA. Understanding and responding to disparities in HIV and other sexually transmitted infections in African Americans. Lancet. 2008;372:337-340.

7. Fleming DT, Wasserheit JN. From epidemiological synergy to public health policy and practice: the contribution of other sexually transmitted diseases to sexual transmission of HIV infection. Sex Transm Inf. 1999;75:3-17.

8. Aholou TM, McCree DH, Oraka E, et al. Sexual risk and protective behaviors among reproductive-aged women in the United States. J Womens Health. 2017;26:1150-1160.

9. Reece M, Herbenick D, Schick V, et al. Condom use rates in a national probability sample of males and females ages 14 to 94 in the United States. J Sex Med. 2010;7(5 Suppl):266-276.

10. Centers for Disease Control and Prevention. Evidence of HIV treatment and viral suppression in preventing the sexual transmission of HIV. 2017. Available at https://www.cdc.gov/hiv/pdf/risk/art/cdc-hiv-art-viralsuppression.pdf Accessed May 22, 2018.

11. Bush S, Magnuson D, Rawlings MK, et al. (2016). Racial characteristics of FTC/TDF for pre-exposure prophylaxis (PrEP) users in the U.S. Presented at: American Society for Microbiology/Conference on Antimicrobial Agents and Chemotherapy Annual Meeting; June 16-20, 2016; Boston, MA. http://www.natap.org/2016/HIV/062216_02.htm Accessed November 8, 2018

12. Geter A, Sutton MY, Hubbard McCree D. Social and structural determinants of HIV treatment and care among black women living with HIV infection: a systematic review: 2005-2016. AIDS Care. 2018;30:409-416.

13. Geter A, Sutton MY, Armon C, et al. Trends of racial and ethnic disparities in virologic suppression among women in the HIV outpatient study, USA 2010-2015. PLoS ONE. 2018;13:e0189973.

14. Stein R, Pierce T, Hollis N, et al. HIV testing and service delivery among black females - 61 health department jurisdictions, United States, 20122014. MMWR. 2016;65:83-85.

15. Beer $\mathrm{L}$, Mattson $\mathrm{CL}$, Bradley $\mathrm{H}$, et al. Understanding cross-sectional racial, ethnic, and gender disparities in antiretroviral use and viral suppression among HIV patients in the United States. Medicine. 2016;95:e3171.

16. Pouget ER, Kershaw TS, Niccolai LM, et al. Associations of sex ratios and male incarceration rates with multiple opposite-sex partners: potential social determinants of HIV/STI transmission. Public Health Reports. 2010; 125(Suppl 4):70-80.

17. Morris M, Kurth AE, Hamilton DT, et al. Concurrent partnerships and HIV prevalence disparities by race: linking science and public health practice. Am J Public Health. 2009;99:1023-1031.

18. Adimora AA, Schoenbach VJ, Doherty IA. HIV and African Americans in the southern United States: sexual networks and social context. Sex Transm Dis. 2006;33(Suppl 7):S39-S45.
19. Adimora AA, Schoenbach VJ, Taylor EM, et al. Sex ratio, poverty, and concurrent partnerships among men and women in the United States: a multilevel analysis. Ann Epidemiol. 2013;23:716-719.

20. Darlington CK, Hutson SP. Understanding HIV-related stigma among women in the southern United States: a literature review. AIDS Behav. 2017;21:12-26.

21. Jones $C P$, Jones $C Y$, Perry GS, et al. Addressing the social determinants of children's health: a cliff analogy. J Health Care Poor Underserved. 2009; 20(4 Suppl):1-12.

22. Washington HA. Medical Apartheid: The Dark History of Medical Experimentation on Black Americans from Colonial Times to the Present. New York, NY: Doubleday Books, 2006.

23. Dovidio JF, Penner LA, Albrecht TL, et al. Disparities and distrust: the implications of psychological processes for understanding racial disparities in health and health care. Soc Sci Med. 2008;67:478-486.

24. Brawner BM. A multilevel understanding of HIV/AIDS disease burden among African American women. J Obstet Gynecol Neonatal Nurs. 2014; 43:633-643.

25. Hill Collins, P. Black Feminist Thought: Knowledge, Consciousness, and the Politics of Empowerment, 2nd ed. New York, NY: Routledge, 2000.

26. Smithers GD. Slave Breeding: Sex, Violence, and Memory in African American History. Gainesville, FL: University Press of Florida, 2012.

27. Prather C, Marshall K, Courtenay-Quirk C, et al. Addressing poverty and HIV using microenterprise: findings from qualitative research to reduce risk among unemployed or underemployed African American women. J Health Care Poor Underserved. 2012;23:1266-1279.

Cite this article as: Bradley ELP, Geter A, Lima AC, Sutton MY, McCree $\mathrm{DH}$ (2018) Effectively addressing human immunodeficiency virus disparities affecting US Black Women, Health Equity 2:1, 329-333, DOI: 10.1089/heq.2018.0038.

\section{Abbreviations Used}

AIDS $=$ acquired immunodeficiency syndrome

$\mathrm{CME}=$ continuing medical education

$\mathrm{HIV}=$ human immunodeficiency virus

$\operatorname{PrEP}=$ pre-exposure prophylaxis

$\mathrm{SDH}=$ social determinants of HIV

$\mathrm{STI}=$ sexually transmitted infection

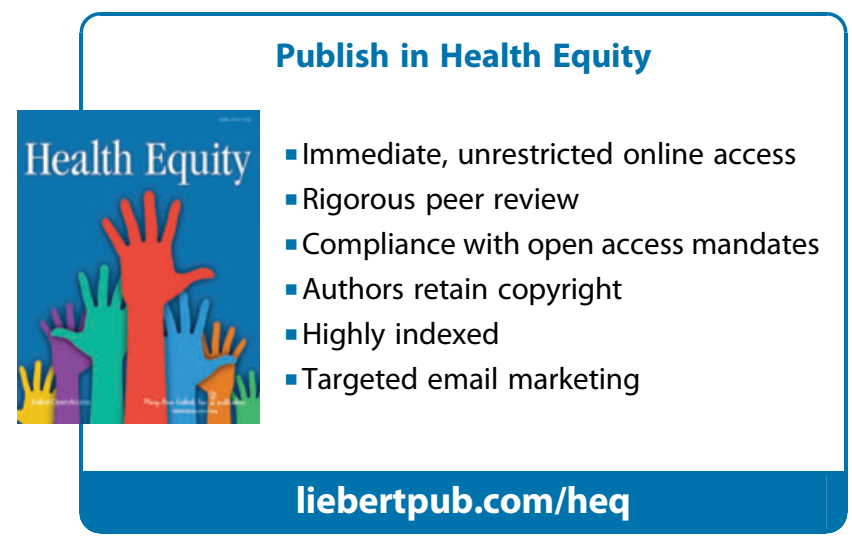

